\section{Prevalence of Severe Atopic Dermatitis in Adults and Children in a Health Area of Madrid, Spain}

\author{
Barroso $\mathrm{B}^{1 *}$, Vera-Berrios $\mathrm{RN}^{1 *}$, Rial $\mathrm{JM}^{1}$, Fariña-Sabaris $\mathrm{MC}^{2}$, \\ Santos LC ${ }^{2}$, Sastre $\mathrm{J}^{1}$ \\ ${ }^{1}$ Allergy Department, University Hospital Fundación Jiménez \\ Díaz, Universidad Autónoma de Madrid, Madrid, Spain \\ ${ }^{2}$ Dermatology Department, University Hospital Fundación \\ Jiménez Díaz, Universidad Autónoma de Madrid, Madrid, Spain \\ *Both authors contributed equally as first authors.
}

J Investig Allergol Clin Immunol 2019; Vol. 29(1): 77-79 doi: 10.18176/jiaci.0339

Key words: Severe atopic dermatitis. Prevalence. Immunosuppressant.

Palabras clave: Dermatitis atópica severa. Prevalencia. Inmunosupresores.

Atopic dermatitis (AD) is one of the most common skin diseases, with a prevalence of up to $25 \%$ in children and $2 \%$ $5 \%$ in adolescents [1]. The worldwide prevalence of $\mathrm{AD}$ in adults, in whom the disease is often severe, has been estimated at $1 \%-3 \%$ [2]. To date, however, the prevalence of moderatesevere $\mathrm{AD}$ remains unclear in both the pediatric and the adult population. Although a recent study estimated the prevalence of severe $\mathrm{AD}$ in adults to be $0.08 \%$ in 3 areas of Spain [3], accurate information on children is lacking.

We present a descriptive study on the prevalence of moderate and severe $\mathrm{AD}$ in patients aged $<18$ and $\geq 18$ years in a health area of Madrid, Spain. Carried out in 2016 and 2017, the primary objective of the study was to provide real-world data from daily clinical practice.

A cross-sectional study was conducted by reviewing electronic medical records from our health area for the years 2016 and 2017. This search included all clinical histories containing the words "atopic dermatitis/atopic eczema" and 1 or more of the following treatments: immunosuppressants (cyclosporine, methotrexate [off-label], azathioprine [off-label], mycophenolate mofetil [off-label]), biologics (omalizumab [off-label], ustekinumab [off-label], dupilumab), systemic corticosteroids, and/or other drugs (immunoglobulins [off-label], apremilast [off-label], UVB phototherapy). We performed retrospective estimations of disease severity using the Investigator's Global Assessment (IGA) scale [4], which classifies the severity of the disease on a scale ranging from 0 to 4 points; only those patients with an IGA score of 3 (moderate $\mathrm{AD}$ ) or 4 (severe $\mathrm{AD}$ ) were included. We also examined the following variables: age, sex, atopic comorbidities, and age at disease onset. Study data were validated to ensure the quality of the results. A descriptive univariate statistical analysis was performed to determine the prevalence and the $95 \%$ confidence interval (CI).

Our health area includes 393418 individuals $\geq 18$ years of age, of whom 160 fulfilled the study criteria. A total of 107 patients were included in 2016 and 117 in 2017 (64 were included in both years). The prevalence of moderate-severe
$\mathrm{AD}$ requiring immunosuppressants in adults was $0.028 \%$ for 2016 and $2017(95 \% \mathrm{CI}, 0.022 \%-0.032 \%$ and $0.024 \%-0.035 \%$, respectively). The prevalence of moderate AD (IGA 3) was $0.008 \%$, and that of severe $\mathrm{AD}$ (IGA 4) was $0.02 \%$ for 2016 and 2017. With regard to the pediatric population, our health area includes 54182 children, 8 of whom met the study criteria, ie, 5 in 2016 and 7 in 2017 (4 [50\%] were included in both years). The prevalence of moderate-severe $\mathrm{AD}$ was $0.01 \%$ for 2016 and 2017 (95\%CI, 0.005\%-0.02\% for both). Other results are summarized in the Table.

Our data illustrate the low prevalence of severe AD in adults and children in our health area. The prevalence of patients with moderate-severe $\mathrm{AD}$ requiring systemic medication was $0.028 \%$ in those aged $\geq 18$ years and $0.015 \%$ among those aged $<18$ years. Although the prevalence of AD is more common in children, severe cases clearly occur more frequently in adulthood, thus increasing the need for systemic medication, including immunosuppressants. A recent study carried out in other areas of Spain found that the prevalence of severe $\mathrm{AD}$ was $0.08 \%$ in adults $(95 \% \mathrm{CI}, 0.07 \%-0.09 \%$ ) [3], although the authors did not report data for children. The difference in prevalence found in the abovementioned study is difficult to explain, since the inclusion criteria were similar. Selection bias, however, may explain this discrepancy. In our study, all patients were carefully selected and had been seen by a specialist in allergology or dermatology, while in the other study, electronic data were obtained from primary care, and patients were not reviewed by specialists.

Of note, only 64 of the 160 patients aged $\geq 18$ years with moderate or severe disease in $2016(40 \%)$ had the same disease severity the following year. Of the children studied, $4(50 \%)$ had consistent degrees of severity over this time. This means than the severity of the disease is not stable in around $50 \%$ of patients with severe $\mathrm{AD}$ and that the need for systemic medication fluctuates. Nevertheless, the prevalence of the disease seems to be constant in both children and adults.

In the study population, onset of $\mathrm{AD}$ was in childhood in $57.02 \%$ of patients and in adulthood ( $\geq 18$ years) in $22.95 \%$. This finding is consistent with a recent systematic review that found that 1 in 4 adults with AD report adult-onset disease [4]. In the US, $10 \%-30 \%$ of childhood $\mathrm{AD}$ patients continue to have the disease in adulthood [5], and of these, $20 \%$ have moderate to severe symptoms. In Denmark, a cohort study [6] including approximately 1300 individuals aged $28-30$ years who had undergone a 15-year follow-up reported persistent $\mathrm{AD}$ in 50\% of those diagnosed in school age. The study also revealed that the significant risk factors for persistent disease compared with outgrowing $\mathrm{AD}$ were early onset (before 2 years), childhood allergic rhinitis, and hand eczema.

Most patients had historically associated atopy-related diseases such as asthma, allergic rhinitis, and food allergy (Table). Of these, asthma and rhinitis were the most prevalent.

Systemic immunosuppressive therapies have been a mainstay in the management of moderate and severe $\mathrm{AD}$ cases [7], with dupilumab [8], a human monoclonal antibody that blocks the signalling of IL-4 and IL-13, being the most recent addition. In our series, systemic corticosteroids were the most common drug used in adults, followed by UVB 
Table. General Characteristics, Comorbidities, and Medication Administered

\begin{tabular}{|c|c|c|c|c|}
\hline \multirow{2}{*}{$\begin{array}{l}\text { Groups } \\
\text { Total population } \\
\text { Year of study }\end{array}$} & \multicolumn{2}{|c|}{$\begin{array}{c}\text { Adults }(\geq 18 \text { y) } \\
393418\end{array}$} & \multicolumn{2}{|c|}{$\begin{array}{c}\text { Children }(<18 \text { y) } \\
54182\end{array}$} \\
\hline & 2016 & 2017 & 2016 & 2017 \\
\hline \# of patients meeting inclusion criteria & $107^{\mathrm{a}}$ & $117^{\mathrm{a}}$ & $5^{\mathrm{b}}$ & $7^{\mathrm{b}}$ \\
\hline $\begin{array}{l}\text { \# of patients with } \\
\text { IGA-3 } \\
\text { IGA-4 }\end{array}$ & $\begin{array}{l}32 \\
75\end{array}$ & $\begin{array}{l}35 \\
82\end{array}$ & $\begin{array}{l}2 \\
3\end{array}$ & $\begin{array}{l}3 \\
4\end{array}$ \\
\hline Estimated prevalence, $\%$ & 0.028 & 0.028 & 0.01 & 0.01 \\
\hline $95 \%$ confidence interval & $0.022-0.032$ & $0.024-0.035$ & $0.005-0.02$ & $0.005-0.02$ \\
\hline $\begin{array}{l}\text { Sociodemographic characteristics of patients } \\
\text { with moderate-severe AD in } 2016 \text { and } 2017\end{array}$ & \multicolumn{2}{|c|}{160 patients } & \multicolumn{2}{|c|}{8 Patients } \\
\hline Mean age, $y$ & 35 & 35 & 12.5 & 12.5 \\
\hline Range: $18-44$ y & 23 & 17 & - & - \\
\hline $45-64$ y & 6 & 5 & - & - \\
\hline$\geq 65 \mathrm{y}$ & 2 & 3 & - & - \\
\hline \multicolumn{5}{|l|}{ Sex (women) } \\
\hline Atopic comorbidities & 40 & 58 & 2 & 2 \\
\hline Asthma & 33 & 39 & 0 & 0 \\
\hline Allergic rhinitis & 36 & 46 & 2 & 2 \\
\hline Nasal polyposis & 0 & 0 & 0 & 0 \\
\hline Food allergy & 16 & 21 & 1 & 3 \\
\hline \multicolumn{5}{|l|}{ Medication administered } \\
\hline Systemic corticosteroids & 72 & 75 & 0 & 3 \\
\hline UVB phototherapy & 26 & 42 & 0 & 0 \\
\hline Cyclosporine $^{\mathrm{c}}$ & 20 & 21 & 4 & 4 \\
\hline Methotrexate & 17 & 21 & 0 & 0 \\
\hline Azathioprine $^{\mathrm{c}}$ & 11 & 7 & 0 & 0 \\
\hline Mycophenolate mofetil $^{c}$ & 1 & 0 & 0 & 0 \\
\hline Omalizumab $^{\mathrm{c}}$ & 3 & 2 & 0 & 0 \\
\hline Dupilumab & 0 & 6 & 0 & 0 \\
\hline Patients hospitalized, \% & 0 & 0 & 0 & 0 \\
\hline
\end{tabular}

Abbreviation: IGA, Investigator's Global Assessment.

${ }^{\mathrm{a}} 64(40 \%)$ patients in both years.

b4 $(50 \%)$ patients in both years.

'Off-label.

phototherapy, cyclosporine, methotrexate, and azathioprine. Dupilumab was used in 6 patients during 2017 (Table). However, children were treated with systemic corticosteroids and/or cyclosporine only.

In conclusion, moderate to severe $\mathrm{AD}$ requiring treatment with systemic immunosuppressants has a low prevalence in adults and children. Of the 160 patients studied, only 64 adults $(40 \%)$ and 4 children $(50 \%)$ had persistent severity for 2 consecutive years. Our findings may be subject to bias resulting from underreporting of the disease.

\section{Acknowledgments}

We are grateful to Oliver Shaw for editorial assistance.

\section{Funding}

The authors declare that no funding was received for the present study.

\section{Conflicts of Interest}

The authors declare that they have no conflicts of interest. 


\section{References}

1. Mallol J, Crane J, von Mutius E, Odhiambo J, Keil U, Stewart A. The International Study of Asthma and Allergies in Childhood (ISAAC) Phase Three: a global synthesis. Allergol Immunopathol (Madr). 2013;41:73-85.

2. Silvestre Salvador JF, Romero-Perez D, Encabo-Duran B. Atopic Dermatitis in Adults: A Diagnostic Challenge. J Investig Allergol Clin Immunol. 2017;27:78-88.

3. Sicras-Mainar A, Navarro-Artieda R, Sánchez L, Sastre J. Prevalence of severe atopic dermatitis in adults in three areas of Spain. J Invest Allergol Clin Immunol. 2018;28:195-7.

4. Lee $H H$, Patel KR, Singam V, Rastogi S, Silverberg Jl. A systematic review and meta-analysis of the prevalence and phenotype of adult-onset atopic dermatitis. J Am Acad Dermatol. 2018 Jun 1. pii: S0190-9622(18)32046-2. doi: 10.1016/j.jaad.2018.05.1241. [Epub ahead of print]

5. Kim JP, Chao LX, Simpson EL, Silverberg JI. Persistence of atopic dermatitis (AD): A systematic review and meta-analysis. J Am Acad Dermatol. 2016;75:681-7.

6. Mortz CG, Andersen KE, Dellgren C, Barington T, BindslevJensen C. Atopic dermatitis from adolescence to adulthood in the TOACS cohort: prevalence, persistence and comorbidities. Allergy. 2015;70:836-45.

7. Roekevisch E, Spuls PI, Kuester D, Limpens J, Schmitt J. Efficacy and safety of systemic treatments for moderate-to-severe atopic dermatitis: a systematic review. J Allergy Clin Immunol. 2014;133:429-38.

8. Sastre J, Dávila I. Dupilumab: A New Paradigm for the Treatment of Allergic Diseases. J Investig Allergol Clin Immunol. 2018;28:139-50.

Manuscript received September 2, 2018; accepted for publication October 10, 2018.

Joaquín Sastre

Hospital Fundación Jiménez Díaz

Av. de los Reyes Católicos, 2 28040 Madrid, Spain

E mail: jsastre@fjd.es 